\title{
Comparison of the potential activities of viral and bacterial chitinases
}

\author{
Suleiman Abulikemu', Aydin Yesilyurt', Donus Gencer ${ }^{2}$, Mehtap Usta ${ }^{3}$ and Remziye Nalcacioglu*
}

\begin{abstract}
Background: Chitin, a long-chain polymer of $\mathrm{N}$-acetylglucosamine, is a major structural component of the insect exoskeleton and the peritrophic membrane (PM). Chitinases are able to effectively break down glycosidic bonds of chitin polymer thus can be used in agriculture to control plant pathogen insects. These enzymes can be synthesized by higher plants, animals, protista, bacteria, and viruses.

Results: In this study, viral and bacterial chitinases were compared for their potential activity on a laboratory test insect. The genes encoding chitinases of Autographa californica nucleopolyhedrovirus (AcNPV) and Cydia pomonella granulovirus (CpGV) were amplified from genomic DNAs by PCR and cloned into the pET-28a (+) expression vector. The chitinase proteins of these 2 viruses (AcNPV-Chi, CpGV-Chi) and Serratia marcescens chitinase C (ChiC) protein which was previously cloned were overexpressed in Escherichia coli. Expressed proteins were purified and confirmed by western blot analysis as 50, 63, and 68 kDa for AcNPV, CpGV, and S. marcescens chitinases, respectively. Enzyme activities of the chitinases were confirmed. Chitinases were also compared to each other in silico. The insecticidal effects of these proteins were evaluated on Galleria mellonella L. larvae. Bioassays were performed on the 3rd instar larvae for each chitinase protein in triplicate. The results showed that although there were differences in enzymatic activities and domain organizations, all 3 microbial chitinases produced almost the same level of insecticidal activity on the test insect. $L C_{50}$ and $L T_{50}$ values were compatible with the mortality results. These results were a preanalysis for comparing the effects of microbial chitinases.
\end{abstract}

Conclusion: Potential activity experiments should be carried out on more insects to provide detailed information on the insecticidal effects of bacterial and viral chitinases.

Keywords: Bacteria, Virus, Chitinase, Potential activity

\section{Background}

Chitin is a linear polysaccharide of $\beta 1$-4-linked $N$-acetylglucosamine, a derivative of glucose, and is the second most abundant biopolymer on earth after cellulose. It is the major polysaccharide present mainly in insects, crustaceans, and fungi. Chitinase, an extracellular enzyme, is able to effectively break down glycosidic bonds of chitin polymer. Chitinase production is widely distributed in various organisms including those that do not contain chitin, like plants, vertebrates, bacteria, and viruses, and

\footnotetext{
* Correspondence: remziye@ktu.edu.tr

${ }^{1}$ Department of Biology, Faculty of Science, Karadeniz Technical University, 61080 Trabzon, Turkey

Full list of author information is available at the end of the article
}

also those that contain chitin such as insects, crustaceans, and fungi. These organisms synthesize chitinases for different purposes such as morphogenesis, pathogenesis, parasitism, and defense (Berini et al. 2018).

Insects are organisms which include both chitin and chitinases together. Chitin is the structural component of the insect exoskeleton, gut lining (perithrophic membrane/PM), salivary gland, trachea, eggshells, and muscle attachment points (Muthukrishnan et al. 2012). At the same time, chitinases are essential for insect survival, molting, or development (Arakane and Muthukrishnan 2010). However, chitinases can also be used exogenously for the biological control of insect pests. Any defect in the cuticle or peritrophic membrane caused by 
chitinases will reduce nutrition and protection against microbial attacks.

Bacteria and viruses are other chitinase producers. Microbial chitinases weaken and disrupt the chitin structures in insects, thus increasing the risk of microbial infection of the host. Bacteria produce chitinases to obtain nitrogen and carbon as a source of nutrients or precursors and parasitism (Rathore and Gupta 2015). Several genera of bacteria, including Serratia (Bahar et al. 2012), Bacillus (Sasi et al. 2020), Streptomyces (Tran et al. 2019), Enterobacter (Sivaramakrishna et al. 2020), and Vibrio (Jahromi and Barzkar 2018), produce chitinase. A few viral chitinases, mainly species from Baculoviridae, are currently known (Ishimwe et al. 2015). Viral chitinases weaken the host barrier structure to facilitate virus infection and release progeny viruses from infected cells. The most widely studied chitinase from baculoviruses belongs to Autographa californica nucleopolyhedrovirus (AcNPV) species (Hawtin et al. 1997). Viral chitinases and most bacterial chitinases belong to family 18 glycohydrolases that belong to a family of multimodular proteins (Berini et al. 2018). AcNPV chitinase is closely related to Serratia marcescens ChiA thus suggesting that baculovirus chitinase may have been acquired from a bacterium found in insect bodies.

The negative effects of chemicals on the ecosystem and on human health force scientists to find alternative solutions against insect pests. Insect pathogenic bacteria and viruses or their bioactive agents are good options to be used as biological pest control materials.

This study aimed to investigate whether there is a difference between viral and bacterial chitinase enzymes in terms of their potential activity.

\section{Methods}

\section{Viral and bacterial strains and insect culture}

In the study, 2 viral and a bacterial chitinase proteins were investigated in terms of their potential activity. Autographa californica nucleopolyhedrovirus (AcNPV) and Cydia pomonella granulovirus (CpGV) species were used for viral chitinase sources. Bacterial chitinase protein (chitinase C) belongs to Serratia marcescens that was previously isolated from dead Helicoverpa armigera (Hubner, 1808) larvae. The $S$. marcescens chitinase gene (accession number: KF823632) was provided cloned into the pET-28a (+) expression vector (Danişmazoğlu et al. 2015). Labreared culture of Galleria mellonella (Linnaeus, 1758). was used in the activity assay. G. mellonella larvae were maintained on an artificial diet (22\% glycerol, $24 \%$ wheat bran, $22 \%$ honey, $24 \%$ honeycomb, and $4 \%$ water) and reared at $26 \pm 2{ }^{\circ} \mathrm{C}$, and $60-70 \%$ relative humidity, with a 14:10-h light:dark photoperiod.
In silico analysis of chitinases

AcNPV (NC_001623.1), CpGV (NC_002816.1), and S. marcescens (KF823632) chitinase proteins were analyzed in terms of their domain content at the NCBI conserved domain search database. Amino acid sequences of chitinases were compared to each other using NCBI protein blast and multiple alignment tools.

\section{Construction of chitinase expressing bacterial vectors}

Viral genomic DNAs were isolated from virus suspensions, using DNeasy Blood \& Tissue Kit (Qiagen, 69506). Specific primers were designed for both AcNPV chitinase (Fw: 5'-GGGGATCCATTCCCGGCACGC-3'; Rv: 5'-GGCTCGAGTTACAGTTCATCTTTAGGT-3') and CpGV chitinase (Fw: 5'-GGGGATCCAAACCCGGCA CACC-3'; Rv: 5'-GGCTCGAGTCATACTGAATTGC ACAC-3'). BamHI and XhoI restriction endonucleases were added to the $5^{\prime}$ ends of forward and reverse primers, respectively. Both chitinase genes (AcNPV-chi, $C p G V$-chi) were amplified by PCR from genomic DNAs. The reactions contain $10 \mathrm{ng}$ of genomic DNA, $2.5 \mu \mathrm{l}$ of both primers of $10 \mu \mathrm{M}, 1 \mu \mathrm{l}$ of $10 \mathrm{mM}$ dNTPs, $10 \mu \mathrm{l} 5 \mathrm{X}$ Phusion HF reaction buffer, and 1 U Phusion HF DNA polymerase. Lastly, the volume was adjusted to $50 \mu \mathrm{l}$ with sterile $\mathrm{dH}_{2} \mathrm{O}$. The reaction program was as follows: an initial denaturation step at $98^{\circ} \mathrm{C}$ for 3 min followed by 30 cycles of $98^{\circ} \mathrm{C}$ for $50 \mathrm{~s}, 55^{\circ} \mathrm{C}$ for $50 \mathrm{~s}, 72^{\circ} \mathrm{C}$ for 1 $\mathrm{min}$, and final extension step at $72^{\circ} \mathrm{C}$ for $10 \mathrm{~min}$. The PCR products were ligated into the PJET1.2/blunt vector according to the manufacturer's instructions. Ligation reactions were transformed into $E$. coli $\mathrm{DH} 10 \beta$ cells, and positive clones were confirmed. The generated recombinant plasmids carrying $A c N P V$-chi and $C p G V$-chi genes were named as $\mathrm{pAcNPV}$ and $\mathrm{pCpGV}$, respectively. The chitinase genes were sequenced by Macrogen Inc. (Amsterdam, the Netherlands). Following the sequence analysis, both chitinase genes containing BamHI and XhoI restriction sites at their $5^{\prime}$ and $3^{\prime}$ ends were introduced into the pET-28a $(+)$ expression vector using the same sites. These plasmids were transformed into $E$. coli BL21 (DE3) competent cells, and recombinant plasmids were selected in the presence of Kanamycin $(50 \mu \mathrm{g} / \mathrm{ml})$.

\section{Over-expression, purification, and western blot analysis of} the recombinant proteins

The AcNPV-Chi, CpGV-Chi, and S. marcescens-ChiC proteins were overexpressed as fusion proteins with the $6 \times$ His-tag at their N-terminal in E. coli BL21 (DE3) cells. Chitinase proteins were purified by using the MagneHis ${ }^{\mathrm{ma}}$ Protein Purification System Kit (Promega) and dialyzed for $24 \mathrm{~h}$ through $1 \mathrm{l}$ of $1 \mathrm{X}$ PBS buffer, $\mathrm{pH}$ 7.5. The identification and purity of the samples were confirmed by $10 \%$ sodium dodecyl sulfate (SDS)-polyacrylamide gel electrophoresis (PAGE) and subsequently Coomassie 


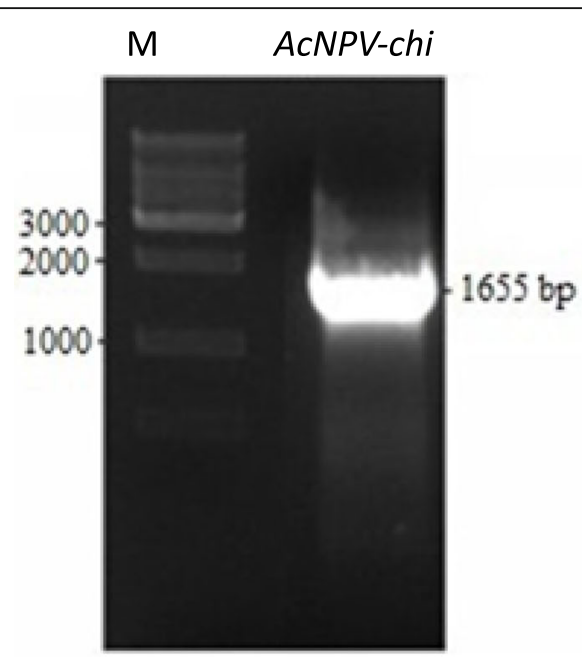

(a)

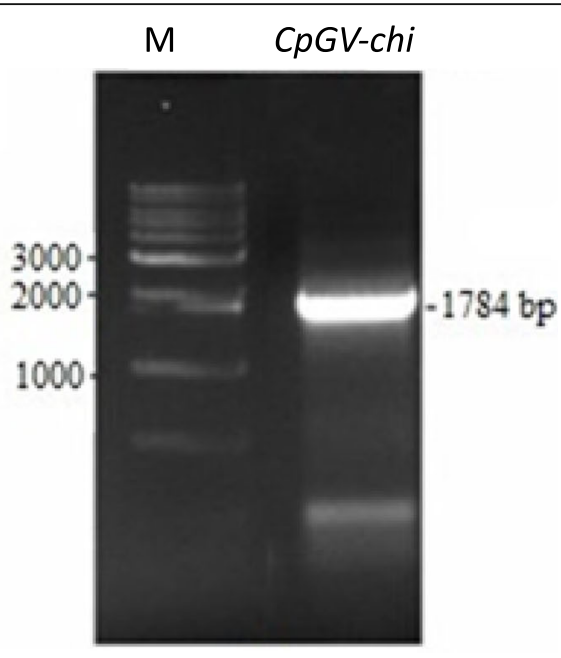

(b)

Fig. 1 PCR amplified AcNPV-chi (a) and CpGV-chi (b) genes. M, 1 kb DNA ladder (Promega)

staining. Western blot analysis was also performed to demonstrate heterologous gene expression at the immunological level. Electrophoresed proteins were transferred to the nitrocellulose membrane. Immunedetection was performed using 1:1000 diluted polyclonal rabbit anti-His-taq antibodies (Abcam) and subsequently 1:1000 diluted polyclonal alkaline phosphataseconjugated goat-anti-rabbit IgG (Millipore). The binding of the antibodies was then visualized with the NBTBCIP substrate system (Roche).

\section{Chitinase activity assay}

Chitinase activities were assayed by using the colorimetric 3,5-dinitrosalicylic acid (DNS) method (Monreal and Reese 1969) with some modifications. The purified bacterial and viral chitinases $(0.5 \mu \mathrm{g})$ were reacted with 150

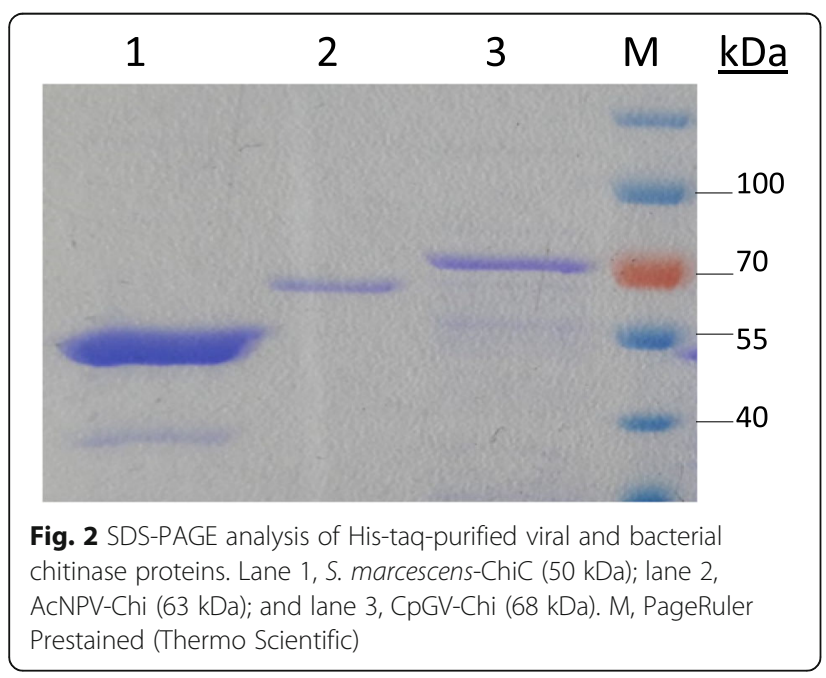

$\mu \mathrm{l}$ of colloidal chitin $(12.5 \mathrm{mg} / \mathrm{ml}$ chitin) as a substrate and incubated at $30^{\circ} \mathrm{C}$ for $3 \mathrm{~h}$. The reactions were terminated by boiling the mixture in the presence of $300 \mu \mathrm{l}$ DNS acid reagent for $5 \mathrm{~min}$. In the control reaction, only substrate and DNS were used. The hydrolysis of chitin was measured at $540 \mathrm{~nm}$ and run with a glucose standard. One unit of the chitinase activity was defined as the amount of enzyme that liberates $1 \mu \mathrm{M}$ of reducing sugar per $1 \mathrm{~min}$ at $30^{\circ} \mathrm{C}$.

\section{Potential activity test}

Proteins were tested on G. mellonella at 5 different concentrations $(1.5,1.8,2,2.5$, and $3 \mu$ g protein) per larvae. Bioassays were performed by 30 larvae (3rd instar) for each concentration in triplicate. The larvae were starved for $12 \mathrm{~h}$ and then fed with an artificial diet inoculated with desired concentrations of protein. After consumption of the inoculated diets, non-inoculated ones were added and incubated at $26 \pm 2{ }^{\circ} \mathrm{C}$. Control group larvae were fed on only $1 \mathrm{X}$ PBS treated diets. Mortalities were recorded daily for 14 days. An experimental design, showing the insecticidal activity tests, is given in Supplementary Fig. 1.

\section{Statistical analysis}

Mortality data were corrected using Abbott's formula (Abbott 1925); $\mathrm{LC}_{50}$ and $\mathrm{LT}_{50}$ values were calculated by Probit analysis using MS Excel (Finney 1952).

\section{Results}

In silico analysis of chitinases

Chitinase proteins were analyzed for their domain contents. The results showed that viral chitinases had similar domain structures to each other but different than 


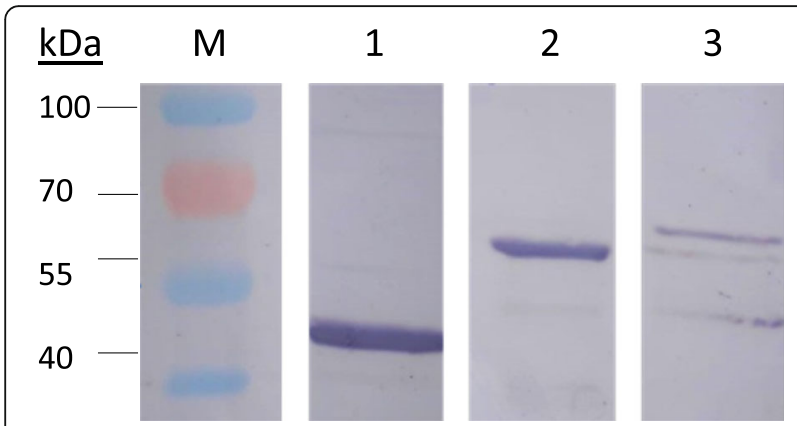

Fig. 3 Western blot analysis of chitinase proteins of Serratia marcescens, AcNPV and CpGV. M, marker (prestained). 1, S. marcescens-ChiC protein (50 kDa); 2, AcNPV-Chi (63 kDa); and 3, CpGV-Chi $(68 \mathrm{kDa})$

that of bacterial chitinase (Supplementary Fig. 2). Viral chitinases contain a ChitinaseA_N domain, whose function is binding to chitin substrat, followed by a glyco_18 domain that catalyses the hydrolysis of 1,4-beta-linkages of $\mathrm{N}$-acetylglucosamine in chitin and chitodextrins. S.marcescens-ChiC protein contains a Chi1 domain, whose function is hydrolyzing the chitin, followed by a COG3979 domain that cleaves soluble oligomers to the di- and trisaccharides. Multiple alignments of amino acid sequences of 3 chitinases together did not produce a significant similarity. Likewise, pairwise alignments of amino acid sequences of bacterial chitinase with either AcNPV or CpGV chitinases did not produce similarity. Although viral chitinases had similar domain organizations, their pairwise identity at amino acid level was only $60 \%$.

\section{Expression, purification, and enzyme activities of} chitinases

The sizes of the DNA fragments amplified by PCR for the $A c N P V$-chi and $C p G V$-chi genes corresponded with the expected sizes of 1655 and $1784 \mathrm{bp}$, respectively (Fig. 1a, b). These products were first cloned into the pJET1.2/blunt vectors and subsequently to the pET-28a $(+)$ vectors (Novagen) individually. AcNPV-Chi, CpGVChi, and S. marcescens-ChiC proteins were expressed in E. coli with a N-terminal 6xHis-tag. Recombinant Histagged proteins were purified, using the MagneHis ${ }^{\mathrm{mm}}$ Protein Purification kit. Purified proteins were analyzed by $10 \%$ SDS-PAGE. The electrophoresis process was performed using 2 gels on which samples were loaded identically. In one of the 2 gels stained with Coomassie Brillant Blue, S. marcescens-ChiC, AcNPV-Chi, and CpGV-Chi proteins were observed at sizes of 50,63 , and $68 \mathrm{kDa}$, respectively, as expected (Fig. 2). The other gel was used for western blot analysis using histidine antibody, which facilitates seeing these proteins by binding to the histidine tag attached to the $\mathrm{N}$-terminal of the proteins. As a result of this analysis, expected chitinase protein sizes were observed on the membrane (Fig. 3). Chitinase activities of these purified proteins, tested by the DNS method, were determined as colorimetric in a spectrometer (Fig. 4).

\section{Potential activity of chitinase proteins}

To analyze the potential activity of AcNPV-Chi and CpGV-Chi and S. marcescens ChiC proteins, G. mellonella larvae were fed on purified and dialyzed proteins. The results showed that the effects on G. mellonella larvae were not much different from each other. However, CpGV-Chi, at 2 and $2.5 \mu \mathrm{g} /$ larvae concentrations, produced a slight high mortality on insects (Fig. 5). The daily number of dead insects was recorded. Mortality effects of chitinase proteins over time were also examined (Fig. 6). $\mathrm{LC}_{50}$ and $\mathrm{LT}_{50}$ values were correlated with the mortality results (Tables 1 and 2).

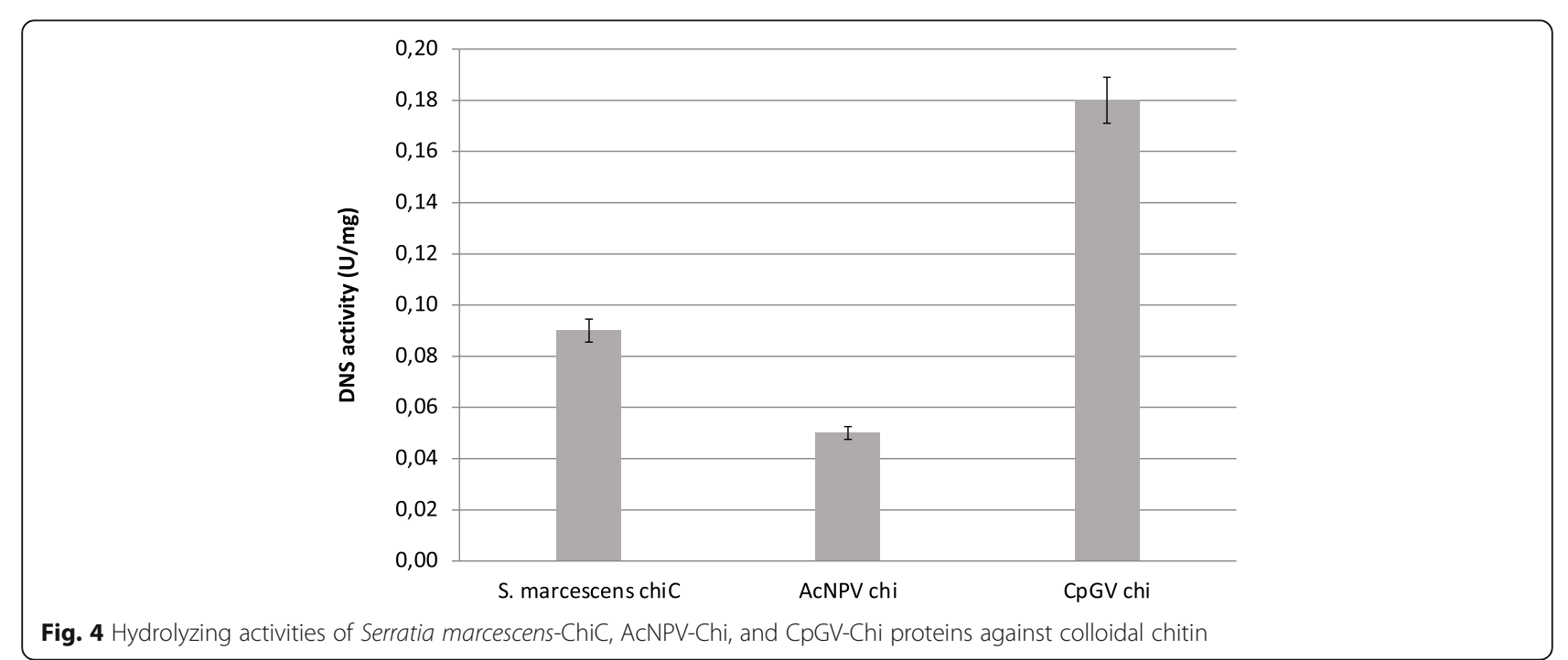




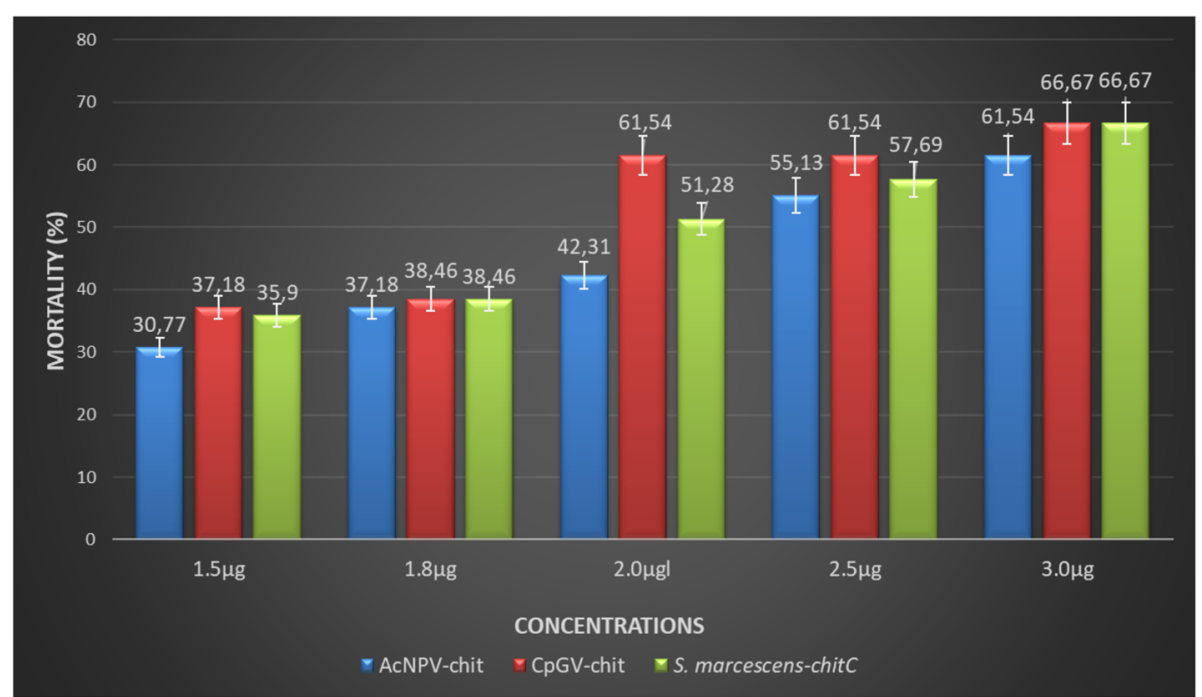

Fig. 5 Insecticidal activity of purified AcNPV-Chi, CpGV-Chi, and Serratia marcescens-ChiC proteins at different concentrations on the 3rd instar Galleria mellonella larvae

\section{Discussion}

Potential effects of chitinase proteins which belong to Autographa californica nuleopolyhedrovirus (AcNPV), Cydia pomonella granulovirus (CpGV), and Serratia marcescens were tested and compared to each other. The results showed that the potential effects of all 3 chitinases were comparable, with only a slightly high mortality rate caused by CpGV chitinase. Increased chitinase concentration produced high mortality rates.

Amino acid sequence alignments of chitinases showed that $S$. marcescens-ChiC and viral chitinases did not show significant similarity to each other. Also, domain positions were opposite in S. marcescens-ChiC and viral chitinases, while the glyco_18 and GH_18 domains located at the $\mathrm{C}$ terminal of viral chitinases showed similar domains located at the $\mathrm{N}$ terminal of $S$. marcescensChiC. S.marcescens-ChiA, structurally analyzed previously by Danişmazoğlu et al. (2015), had a similar domain organization to those of AcNPV-Chi and CpGVChi.

Enzyme activities of chitinases were confirmed using the DNS method before activity analysis. The results showed that CpGV-Chi activity was higher than S. marcescens-ChiC activity and much higher than AcNPV-Chi

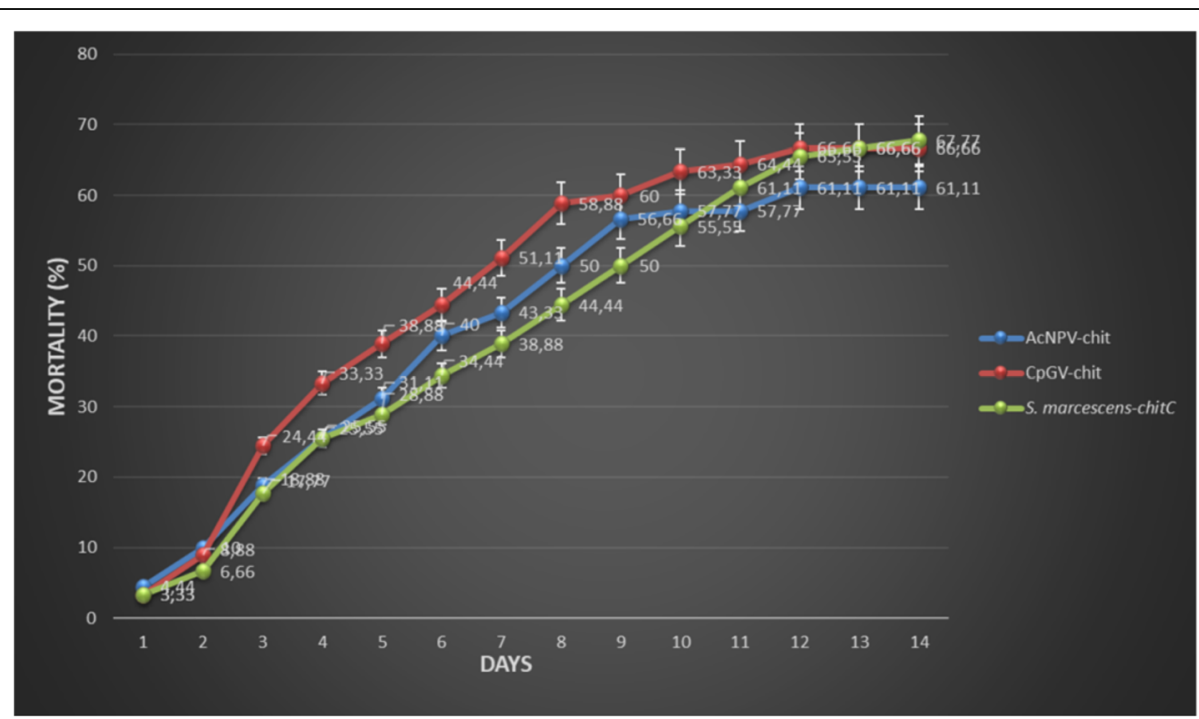

Fig. 6 Mortality rates of purified AcNPV-Chi, CpGV-Chi, and Serratia marcescens-ChiC proteins on Galleria mellonella larvae depending on time. Mortality rates were carried out using the $2.5 \mu \mathrm{g}$ per larvae protein concentration 
Table 1 LC 50 values of AcNPV-Chi, CpGV-Chi, and Serratia marcescens-ChiC proteins

\begin{tabular}{lllll}
\hline Chitinase & LC $_{\mathbf{5 0}}(\mathbf{n g})$ & Slope \pm SE & df & $\mathbf{X}^{\mathbf{2}}$ \\
\hline AcNPV-Chi & 2318.318 & $2.753 \pm 0.066$ & 3 & 0.997 \\
CpGV-Chi & 1958.961 & $2.686 \pm 0.067$ & 3 & 0.658 \\
S.marcescens-ChiC & 2095.064 & $2.734 \pm 0.066$ & 3 & 0.944 \\
\hline
\end{tabular}

activity. Although there was a small difference between bacterial and viral chitinases in terms of potential activity results, this difference was also detected in the in vitro enzyme activity assay.

Chitinase protein of AcNPV in conjunction with virusencoded cathepsin caused liquefaction of the Trichoplusia $n i$ (Hubner, 1803) larvae in the latter stages of infection (Hawtin et al. 1997). They showed that infections of T. ni larvae with mutant viruses lacking either chitinase or cathepsin did not cause liquefaction of dead insect bodies. In the present study, dead G. mellonella larvae showed softening, but the body remained intact for several days after death. Failure to observe body liquefaction in dead G. mellonella larvae may be due to not using cathepsin protein with chitinase in infections. In another study, the AcNPV chitinase A (ChiA) gene was expressed in $E$. coli cells, subsequently purified and tested on Bombyx mori (Linnaeus, 1758) larvae at a dose of $1 \mu \mathrm{g} / \mathrm{g}$ of larval body weight. They obtained $100 \%$ mortality and concluded that AcNPV-ChiA may offer interesting new opportunities for pest control (Raw et al. 2004). Daimon et al. (2007) constructed a recombinant Bombyx mori NPV (BmNPV) in which BmNPV ChiA was replaced by $\mathrm{CpGV}$ ChiA. This recombinant BmNPV was tested on B. mori larvae. Their results showed that CpGV ChiA were able to complement the absence of BmNPV ChiA in the terminal liquefaction process of infected larvae.

The potential activity of $S$. marcescens ChiC protein, used in this study, was previously studied by Danişmazoğlu et al. (2015), who tested the mortality not only on ChiC protein but also chiA and chiB proteins of $S$. marcescens on Malacosoma neustria (Linnaeus, 1758) and Helicoverpa armigera larvae. Among these 3 chitinase proteins, ChiC produced the highest potential activity against used insect larvae. At another study, the same $S$. marcescens chitinase $\mathrm{B}$ and $\mathrm{C}$ proteins were transformed

Table $2 \mathrm{LT}_{50}$ values of AcNPV-Chi, CpGV-Chi, and Serratia marcescens-ChiC proteins ${ }^{a}$

\begin{tabular}{lll}
\hline Chitinase & $\mathbf{L T}_{\mathbf{5 0}}$ (days) & Slope \pm SE \\
\hline AcNPV-Chi & $8.600(6.55-11.28)$ & $1.882 \pm 0.060$ \\
CpGV-Chi & $7.199(5.62-9.20)$ & $2.086 \pm 0.055$ \\
S.marcescens-ChiC & $8.639(6.76-11.04)$ & $2.110 \pm 0.054$ \\
\hline
\end{tabular}

${ }^{\mathrm{a}} \mathrm{LT}_{50}$ values were calculated using the $2.5 \mu \mathrm{g}$ per larvae protein concentration. to Bacillus thuringiensis strains containing crystal proteins, and the potential activity of the recombinant bacteria was tested on G. mellonella larvae (Ozgen et al. 2013). Mortality rates recorded were between 45 and $55 \%$. In the present study, the chitinase C protein of $S$. marcescens was tested on G. mellonella larvae and displayed around $50 \%$ potential activity at $2 \mu \mathrm{g}$ protein amount per larvae. Insecticidal proteins, which provide important tools to control insect pests, can be used in conjunction with microorganisms. Virion-free proteins of a GV (GVPs) were used with an NPV on $H$. armigera larvae (Shigeyuki and Chie 2007). Their results showed that the addition of GVPs successfully enhanced NPV infectivity in $H$. armigera without any negative influence on NPV pathogenicity.

\section{Conclusion}

Two viral and a bacterial isolates were compared to each other in terms of their potential activity. The results showed that all the 3 chitinases produced close insecticidal effects on G. mellonella larvae. Testing these proteins on more insects would be more informative to conclude which microbial chitinases are more effective. Chitinases and other insecticidal proteins alone or in conjunction with other control agents may contribute to the development of new biopesticides.

\section{Abbreviations}

AcNPV: Autographa californica nucleopolyhedrovirus; AcNPV-chi: AcNPV chitinase; CpGV: Cydia pomonella granulovirus; CpGV-chi: CpGV chitinase; S. marcescens-chiC: Serratia marcescens chitinase C; IPM: Integrated pest management

\section{Supplementary Information}

The online version contains supplementary material available at https://doi. org/10.1186/s41938-021-00435-0.

Additional file 1: Supplementary Fig. 1. Experimental design of insecticidal activity test. Five different virus concentration (indicated on tubes) was used. Every virus concentration was tested on 30 larvae for one trial. Experiment was repeated three times.

Additional file 2: Supplementary Fig. 2. Conserved domain structures of Serratia marcescens-ChiC (A), AcNPV-Chi (B), and CpGV-Chi (C) proteins.

\section{Acknowledgements}

Not applicable.

Authors' contributions

SA performed the protein expression and purification and potential activity experiments and wrote the manuscript. AY and DG performed the cloning of the chitinase genes and evaluated the data. MU contributed to the data elaboration and reviewed the manuscript. RN conceived and designed the research and reviewed the manuscript. All authors read and approved the final manuscript.

Funding

Not applicable.

Availability of data and materials Not applicable. 


\section{Declarations}

Ethics approval and consent to participate

Not applicable.

\section{Consent for publication}

Not applicable.

\section{Competing interests}

The authors declare that they have no competing interests.

\section{Author details}

${ }^{1}$ Department of Biology, Faculty of Science, Karadeniz Technical University, 61080 Trabzon, Turkey. ${ }^{2}$ Department of Property Protection and Security, Salpazari Vocational School, Trabzon University, Trabzon, Turkey. ${ }^{3}$ Department of Health Care Services, Tonya Vocational School, Trabzon University, Trabzon, Turkey

Received: 2 February 2021 Accepted: 10 May 2021

Published online: 12 June 2021

\section{References}

Abbott WS (1925) A method of computing the effectiveness of an insecticide. J Econ Entomol 18:265-267

Arakane Y, Muthukrishnan S (2010) Insect chitinase and chitinase-like proteins. Cell Mol Life Sci 67(2):201-216

Bahar AA, Sezen K, Demirbağ Z, Nalcacioglu R (2012) The relationship between insecticidal effects and chitinase activities of Coleopteran-originated entomopathogens and their chitinolytic profile. Ann Microbiol 62:647-653

Berini F, Katz C, Gruzdev N, Casartelli M, Tettamanti G, Marinelli F (2018) Microbial and viral chitinases: attractive biopesticides for integrated pest management. Biotechnol Adv 36(3):818-838

Daimon T, Katsuma S, Kang W, Shimada W (2007) Functional characterization of chitinase from Cydia pomonella granulovirus. Arch Virol 152:1655-1664

Danişmazoğlu M, Demir İ, Sezen K, Muratoğlu H, Nalçacioğlu R (2015) Cloning and expression of chitinase $A, B$, and $C$ (chi $A$, chiB, chiC) genes from Serratia marcescens originating from Helicoverpa armigera and determining their activities. Turk J Biol 39:78-87

Finney DJ (1952) Probit analysis: a statistical treatment of the sigmoid response curve. Cambridge University Press, Cambridge, p 256

Hawtin R, Zarkowska T, Arnold K, Thomas C, Gooday G, King L, Kuzio J, Possee R (1997) Liquefaction of Autographa californica nucleopolyhedrovirus infected insects is dependent on the integrity of virus-encoded chitinase and cathepsin genes. Virology 238(2):243-253

Ishimwe E, Hodgson JJ, Clem RJ, Passarelli AL (2015) Reaching the melting point: degradative enzymes and protease inhibitors involved in baculovirus infection and dissemination. Virology 479-480:637-649

Jahromi ST, Barzkar N (2018) Marine bacterial chitinase as sources of energy, ecofriendly agent, and industrial biocatalyst. Int J Biol Macromol 120:2147-2154

Monreal I, Reese E (1969) The chitinase of Serratia marcescens. Can J Microbiol 5: 689-696

Muthukrishnan S, Merzendorfer H, Arakane Y, Kramer KJ (2012) In: Gilbert LI (ed) Chitin metabolism in insects. Gilbert L.I. (Ed.), Insect molecular biology and biochemistry. Elsevier Inc, San Diego, pp 193-235

Ozgen A, Sezen K, Demir I, Demirbag Z, Nalcacioglu R (2013) Molecular characterization of chitinase genes from local isolate of Serratia marcescens and their contribution to the insecticidal activity of Bacillus thuringiensis strains. Curr Microbiol 67(4):499-504

Rathore AS, Gupta RD (2015) Chitinases from bacteria to human: properties, applications, and future perspectives. Enzyme Res 2015:791907

Raw R, Fiandra L, Giordana B, de Eguileor M, Congiu T, Burlini N, Arciello S, Corrado G, Pennacchio F (2004) AcMNPV ChiA protein disrupts the peritrophic membrane and alters midgut physiology of Bombyx mori larvae. Insect Biochem Mol Biol 34(11):1205-1213

Sasi A, Duraipandiyan N, Marikani K, Dhanasekaran S, Al-Dayan N, Venugopal D (2020) Identification and characterization of a newly isolated chitinaseproducing strain Bacillus licheniformis SSCL-10 for chitin degradation. Archaea 2020:1-9

Shigeyuki M, Chie G (2007) Enhancement of nucleopolyhedrovirus infectivity against Mamestra brassicae (Lepidoptera: Noctuidae) by proteins derived from granulovirus and a fluorescent brightener. J Econ Entomol 100(4):10751083

Sivaramakrishna D, Bhuvanachandra B, Mallakuntla MK, Das SN, Ramakrishna B, Podile AR (2020) Pretreatment with $\mathrm{KOH}$ and $\mathrm{KOH}$-urea enhanced hydrolysis of a-chitin by an endo-chitinase from Enterobacter cloacae subsp. cloacae. Carbohydr Polym 235:1 15952. https://doi.org/10.1016/j.carbpol.2020.115952

Tran TN, Doan CT, Nguyen VB, Wang SY (2019) The isolation of chitinase from Streptomyces thermocarboxydus and its application in the preparation of chitin oligomers. Res Chem Intermed 45:727-742

\section{Publisher's Note}

Springer Nature remains neutral with regard to jurisdictional claims in published maps and institutional affiliations.

\section{Submit your manuscript to a SpringerOpen ${ }^{\circ}$ journal and benefit from:}

- Convenient online submission

- Rigorous peer review

- Open access: articles freely available online

- High visibility within the field

- Retaining the copyright to your article

Submit your next manuscript at $\boldsymbol{\nabla}$ springeropen.com 